\title{
Does an acute bout of high intensity interval exercise suppress appetite in obese women?
}

\author{
Sepideh Khalaj ${ }^{\mathrm{ABCDE}}$, Bahman Mirzaei ${ }^{\mathrm{ABCDE}}$
}

University of Guilan, Rasht, Iran

Authors' Contribution: A - Study design; B - Data collection; C - Statistical analysis; D - Manuscript Preparation; E - Funds Collection.

\begin{abstract}
Purpose:

The aim of this study was to investigate the 24 hour response of appetite and energy intake and the amount of Agouti-Related Protein to the high intensity interval exercise in obese untrained women.

Material:

Ten obese untrained women were voluntarily selected according to the criteria of the research and evaluated in two experimental and control sessions. Blood samples were collected in two sessions of control and experimental group in five stages. Also, the appetite questionnaire was completed in 9 steps. Also, energy intake was recorded by them during the day.

Results: $\quad$ Agouti-Related Protein increased significantly in experimental session immediately after exercise compared to the control session $(p<0.05)$. In the Visual analog scale, the feeling of hunger and desire to eat decreased significantly immediately after exercise and before lunch in the experimental session $(p<0.05)$. While feeling of satiety and fullness were significantly higher immediately after exercise and before lunch $(p<0.05)$, in other words, the desire to eat was reduced. Also, exercise significantly reduced energy intake in the experimental session compared to control session $(p<0.05)$. The amount of protein consumption, carbohydrate, and fat decreased in the experimental session compared to the control session, but this decrease was not statistically significant ( $p>0.05)$.

Conclusions: $\quad$ Although a session of high intensity interval exercise resulted in reduced energy intake, but this reduction was not related to just one macronutrient. Hunger and desire to eat decreased after exercise and before lunch but the Agouti-Related Protein increased after exercise.

Keywords: obesity, appetite, energy intake, AgRP, intensity interval exercise.
\end{abstract}

\section{Introduction}

Over the years, obesity is considered as a worldwide problem, and is defined as abnormal or excessive fat accumulation that impairs health [1]. However, recent reports indicate that obesity rates have doubled worldwide in recent years and women are more likely to be obese or overweight than men [2]. Obesity is a major risk factor for mortality mainly from cardiovascular disease [3], type 2 diabetes [4], types of cancer [5], and other diseases. In addition, the pathogenesis of human obesity results from a bad regulation of energy intake and energy expenditure that affects the balance of daily energy and ultimately leads to body weight gain [6].

Research has shown that physical activity is one of the ways to regulate energy balance in the body and evidence suggests that both acute exercise and regular exercise training directly generate negative energy balance and also reduce appetite and the total energy consumption and affect the levels of a number appetite related peptides [7]. However, the hypothalamus plays a key role in regulating appetite, food intake, and energy homeostasis in humans [8]. The hypothalamus contains a group of neurons that secretes specific neuropeptides affecting eating behaviors [9]. Hypothalamic neuropeptides are factors that affect appetite, eating behavior, and energy balance, which are divided into two groups of appetite stimulus and appetite suppressant; one of these hormones is the Agouti-Related Protein (AgRP) which is known as one of the most important orexigenic hormones [10]. Thus appetite is

\footnotetext{
(c) Khalaj Sepideh, Mirzaei Bahman, 2020

doi:10.15561/26649837.2020.0405
}

controlled by a series of complex processing in the brain and several peripheral secretion hormones [11]. AgRP is a 132 amino acid peptide that is secreted from the midline of the arterial nucleus of the hypothalamus and the inner region of the adrenal gland [12]. This hormone is a candidate gene for human obesity and a strong appetite stimulant, and evidence suggests that it plays a large role in receiving and choosing food, regulating weight, and energy hemostasis [13]. It has also been reported that it has both acute and long-term effects on food intake [12].

As mentioned above, some conditions such as physical activity and exercise can create changes in appetite, energy intake, and peptides that affect energy balance and adjustment. In this case Carnier et al. examined the long-term effect of aerobic training and the combination of aerobic and resistance training on anorexigenic and orexigenic hormones in obese adolescent and concluded that in both groups, daily energy intake decreased although in combination group the concentration of AgRP increased [14]. In another study that investigated the effect of treadmill running on plasma concentration of AgRP in rats, the results showed that plasma AgRP levels increased with running [15]. Also researches evaluated the response of AgRP to a single session of circuit resistance exercise in college men and finally the results indicated that AgRP plasma levels increased immediately after exercise and returned to pre-exercise levels during recovery [16].

As there are only few studies on the response of this hormone to exercise and women are more likely to be obese or overweight than men; therefore, the main challenge for researchers is to control obesity in obese 
women; whereas, the caloric intake within 24 hours can be very important in controlling this process. Considering that high intensity interval exercise (HIIE) has been recently recognized as a high performance exercise method in obese individuals and this type of exercise affects individual's appetite greatly, also most individuals tend to choose HIIE instead of continuous exercise [17, 18]; therefore the present study attempts to investigate the 24 hour response of appetite and energy intake and the amount of Agouti-Related Protein to the high intensity interval exercise in obese untrained women.

\section{Materials and Methods}

Subject design

15 obese untrained women (age: $33 \pm 8.47$ years, height: $161.92 \pm 4.12 \mathrm{~cm}$, weight: $85.75 \pm 3.40 \mathrm{~kg}$, body fat: $39.80 \pm 1.93 \%$, body mass index: $32.48 \pm 1.59 \mathrm{~kg} / \mathrm{m}^{2}$ ) voluntarily participated in this study. Eventually five of them were excluded due to incomplete cooperation. The criteria for participation in the research were as follows: 1) obese (BMI: 30-39.9 kg/m²) and untrained. 2) Weight stability within the last 6 months. 3) Not using a specific drug that effects on appetite. 4) Not dieting. 5) Sufficient ability to participate in research. First, after coordination with the subjects, initial measurements including height, weight, body mass index, body fat percentage, blood pressure, and heart rate were performed one day before the subjects were invited to study. Then, written consent was taken from subjects and the medical and sports records questionnaire were completed by them. It should be noted that all stages of research were confirmed by the Ethics Committee of Guilan University of Medical Sciences (IR.GUMS.REC.1398.081). Table 1 describes the characteristics of the study participants.

Table 1. Characteristics of the study participants

\begin{tabular}{ll}
\hline Characteristics & Mean \pm SD \\
\hline Age $(\mathrm{y})$ & $33 \pm 8.47$ \\
Height $(\mathrm{cm})$ & $161.92 \pm 4.12$ \\
Weight $(\mathrm{kg})$ & $85.75 \pm 3.40$ \\
Body fat $(\%)$ & $39.80 \pm 1.93$ \\
BMl $\left(\mathrm{kg} \cdot \mathrm{m}^{2}\right)$ & $32.48 \pm 1.59$ \\
\hline
\end{tabular}

Design and exercise protocol

At first, the subjects were evaluated in the form of the control group and then examined with an interval of 10 days in the experimental group form. In the experimental session, the subjects performed 10 exercises, 1 minute running on treadmill at $90 \% \mathrm{HRmax}$ and with 1 minute rest interval between exercises at 30\% HRmax [1]. It should be noted that subjects did not perform any exercises in the control session and only blood samples were taken from them and the visual analog scale (VAS) was completed by them; energy intake was also reported.

Anthropometric measurements

A digital scale with a precision of $0.01 \mathrm{~kg}$ was used to evaluate the subject's weight. A wall-mounted stadiometer with a precision of $0.01 \mathrm{~cm}$ was used to measure height.
For measurements of height and weight, the subjects were bare foot and wearing slight clothing. Body mass index was calculated as body weight $(\mathrm{kg})$ divided by height squared $\left(\mathrm{m}^{2}\right)$. Percentage of body fat was measured using caliper Lafayette at three anatomical landmarks (tight, triceps, suprailiac). All measurements were taken from the right side of the body and measured three times to reduce the measurement error.

Blood sampling and biochemical analysis

Blood samples were collected from the antecubital vein at five stages; first stage: morning before breakfast (before exercise), second stage: after exercise, third stage: before lunch, fourth stage: before dinner, and fifth stage: one hour after dinner. Plasma was separated by centrifugation; the samples were then stored at $-80^{\circ}$ $\mathrm{C}$ until testing time. Plasma AgRP was measured using a Human Agouti Related Protein (AgRP) ELISA Kit (HANGZHOU EASTBIOPHARM, china, sensitivity $1.01 \mathrm{ng} / \mathrm{ml})$.

\section{Subjective appetite sensations}

The VAS is also completed before and after breakfast (8:00), before and after the exercise (11:00), before and after lunch (12:15), before and after dinner (19:00), and one hour after dinner [19]. Participants were asked to rate the amount of satiety, fullness, hunger, and desire to eat using the VAS (0 to $100 \mathrm{~mm}$ ). Participants rated their appetite perceptions by placing a mark on a $100 \mathrm{~mm}$ continuum with descriptors positioned at either end. The validity and reliability of this questionnaire have been proven by Flint et al [20].

\section{Energy intake}

Energy intake was measured using the registration of foods in the consumables recording sheet. The amounts of each food consumed was reported to gram .Then each food was coded according to the instructions of the N4software: by entering the code for each foodstuff in the software and specifying the amount of foods consumed to gram, the Calories related to that foodstuff to the kilocalories, and the amount of macronutrients (protein, carbohydrate, fat) as well as the total caloric intake of the whole day were provided by the software

Statistical analysis

The Shapiro-Wilk test was used to verify the normality of the data. Parametric descriptive data were presented in mean and standard deviation (SD). Twoway repeated measures analysis of variance (ANOVA) followed by Bonferroni's method was used to analyse the data from the VAS (hunger, satiety, fullness, desire to eat) and AgRP. T-test method was used to analyse the energy intake and macronutrients data. All statistical procedures were performed using SPSS version .20.0.

\section{Results}

\section{Agouti-related protein}

Based on Fig 1 plasma levels of AgRP increased significantly in experimental session immediately after exercise compared to control session $(p<0.05)$, but no significant difference was observed in other stages of measurement compared to control sessions $(\mathrm{p}>0.05)$. 


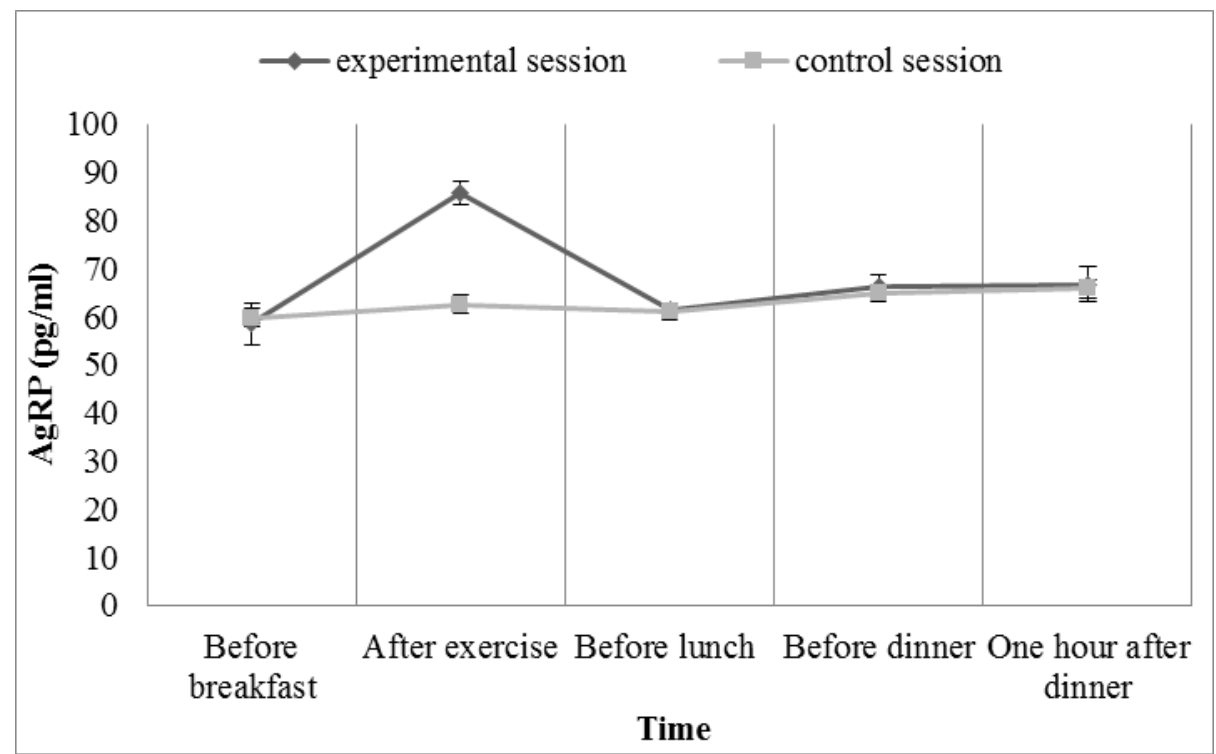

Figure 1. Plasma concentration of AgRP in the control and experimental session. Values are mean $\pm S D(n=10)$.

\section{Appetite questionnaire}

According to the information presented in Fig 2-5, in the exercise session, the rating of hunger and desire to eat immediately after exercise and before lunch significantly decreased compared to the control session $(p<0.05)$, while rating of satiety and fullness were significantly higher immediately after exercise and before lunch $(\mathrm{p}<0.05)$. In other words, desire to eat was reduced. while no significant difference was observed before breakfast, after breakfast, before exercise, after lunch, after dinner, and one hour after dinner for four components (hunger, satiety, fullness, desire to eat) compared to control session ( $p>0.05)$.

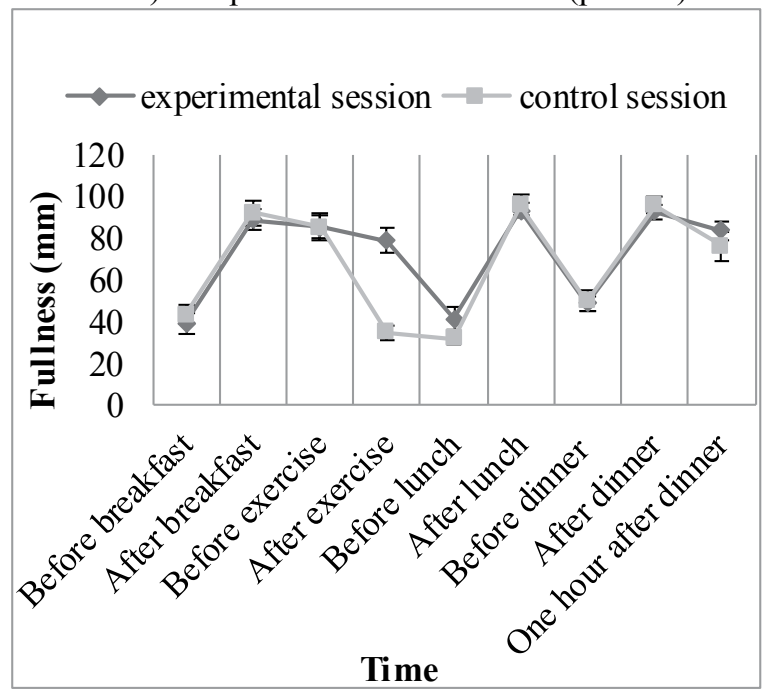

Figure 2. Rating of fullness in the control and experimental session. Values are mean $\pm S D(n=10)$.

\section{Energy intake and macronutrients}

As shown in Fig 6 and Table 2 in the experimental session, total energy intake during the day was significantly lower than the control session $(\mathrm{p}<0.05)$, while according to Table 3 the protein, carbohydrate and fat intake decreased in experimental group, but this decrease was not statistically significant ( $\mathrm{p}>0.05)$.

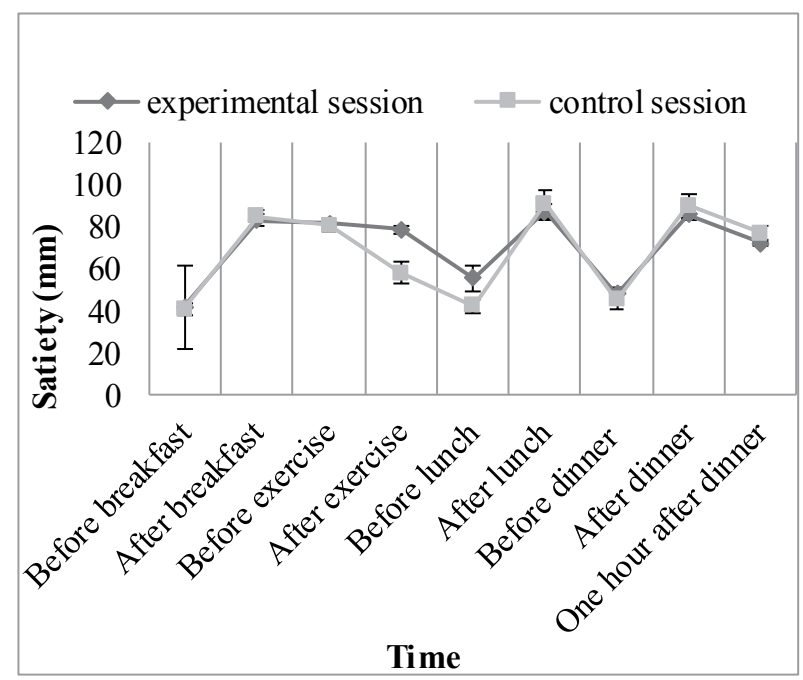

Figure 3. Rating of satiety in the control and experimental session. Values are mean $\pm S D(n=10)$.

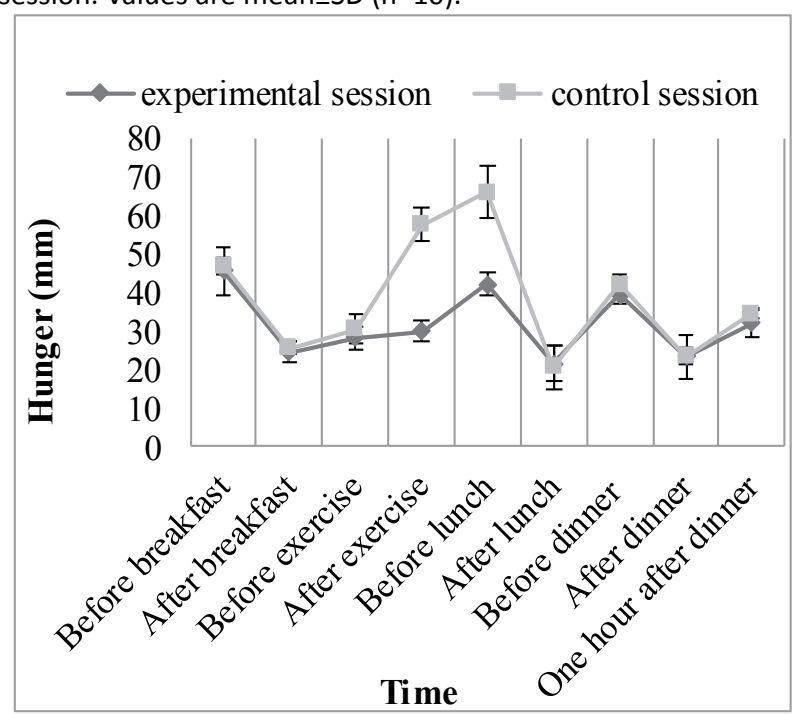

Figure 4. Rating of hunger in the control and experimental session. Values are mean $\pm S D(n=10)$. 


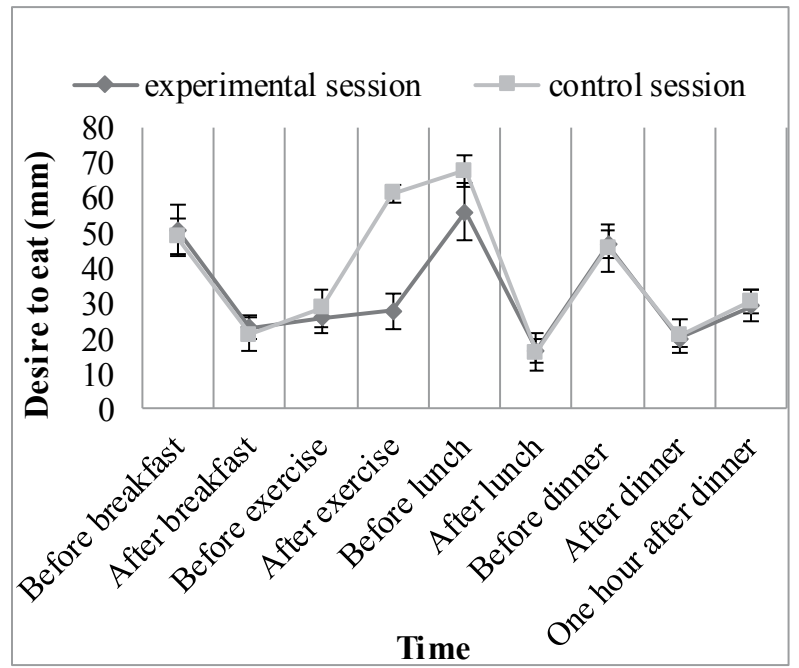

Figure 5. Rating of desire to eat in the control and experimental session. Values are mean $\pm S D(n=10)$.

\section{Discussion}

Obesity is rising now in developing countries and in developed countries [21]. Obesity develops when energy intake is more than energy expenditure, given that exercise is an important component of daily energy balance [22]. Since exercise affects eating behavior, and appetite regulation is one of the important issues for weight control in exercise physiology, the purpose of this study was to determine the 24 hour response of appetite and energy intake and the amount of Agouti-Related Protein to the high intensity interval exercise in obese untrained women.

Exercise and Agouti-related protein

In the current study, plasma levels of AgRP in the experimental session, immediately after HIIE significantly increased compared to the control session and baseline levels and the lunch meal, dinner meal, and one hour after dinner. It was also close to its baseline level which was even higher than the baseline level, but this amount was not statistically significant. The reason for the increase in AgRP seems to be that exercise and physical activity greatly disturb the energy balance of the cell. During exercise, muscle energy requirements increase dramatically. This need must be met in a way that allows the muscle to continue its activity. The disturbance of energy balance increases the expression of AgRP in the hypothalamus which was previously shown by other research [16, 23-25]. It should be noted that little research has been done on the effects of exercise on AgRP on humans. Among the studies that examined the effect of exercise on human plasma AgRP concentration was Ghanbari-Niaki et al. [16] These researchers investigated the effect of one session of a circuit resistance exercise on the concentration of AgRP in male students. The results of their research showed that plasma AgRP level significantly increased immediately after exercise and returned to baseline level during recovery period [16]. This study is in line with the current research. Also, in contradiction with the current research, Ghanbari-Niaki et al. assessed the effect of a session circuit resistance exercise training on serum levels of AgRP in male students and proved that this type of exercise significantly reduced serum levels of AgRP immediately after exercise in subjects [26]. The difference between this research and the present study was the type and intensity of the exercise and the characteristics of subjects. The current study subjects were obese untrained women. In this regard Katsuki et al. compared 30 obese men and women with 30 non-obese men and women and same age of plasma levels

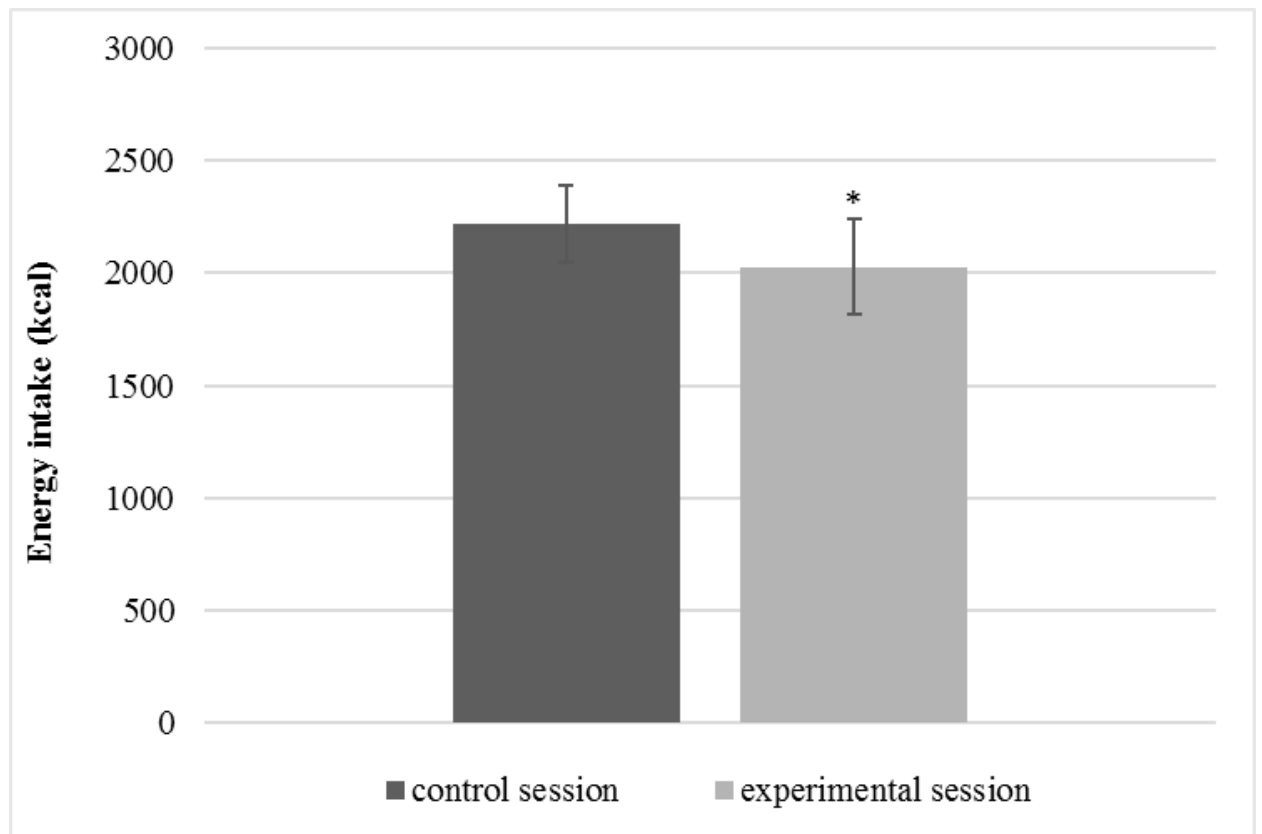

Figure 6. Rating of energy intake in the control and experimental session. Values are mean $\pm S D(n=10) .{ }^{*}=\operatorname{Significant}$ difference between two sessions using the T-test method. 
Table 2. Energy intake in the control and experimental session (Mean \pm SD)

\begin{tabular}{lll}
\hline $\begin{array}{l}\text { Meals } \\
\text { (kcal) }\end{array}$ & $\begin{array}{l}\text { Control Session } \\
(\mathbf{n}=10)\end{array}$ & $\begin{array}{l}\text { Experimental Session } \\
(\mathbf{n}=\mathbf{1 0})\end{array}$ \\
\hline Breakfast meal & $672.432 \pm 115.463$ & $572.480 \pm 177.255$ \\
Breakfast snack & $122.279 \pm 74.742$ & $85.126 \pm 35.928$ \\
Lunch meal & $591.409 \pm 164.280$ & $515.015 \pm 211.051$ \\
Afternoon snack & $156.880 \pm 112.093$ & $190.108 \pm 160.826$ \\
Dinner meal & $538.475 \pm 245.820$ & $549.920 \pm 317.685$ \\
One hour after dinner & $135.728 \pm 155.079$ & $119.563 \pm 116.115$ \\
\hline
\end{tabular}

Table 3. Macronutrients intake in the control and experimental session throughout the day (Mean \pm SD).

\begin{tabular}{lll}
\hline $\begin{array}{l}\text { Macronutrients } \\
\text { (gram) }\end{array}$ & $\begin{array}{l}\text { Control Session } \\
(\mathbf{n = 1 0 )}\end{array}$ & $\begin{array}{l}\text { Experimental Session } \\
(\mathbf{n = 1 0 )}\end{array}$ \\
\hline Carbohydrate & $\mathbf{2 8 4 . 6 6 6 \pm 3 9 . 4 3 2}$ & $266.155 \pm 75.717$ \\
Protein & $92.819 \pm 24.644$ & $77.388 \pm 5.331$ \\
Fat & $74.384 \pm 25.189$ & $67.605 \pm 25.367$ \\
\hline
\end{tabular}

of AgRP. The results of this study showed that plasma concentration of AgRP was higher in both obese men and women than non-obese men and women. The researchers also found that there was a positive correlation between plasma levels of AgRP and BMI [24].

In addition, it has been suggested that increasing AgRP can be considered as an effective factor in the mechanism of glycogen repair and super compensation following exercises [27]. Therefore, considering that the exercise protocol of the present study is considered as a high intensity exercise, it seems that one of the reasons for increasing plasma AgRP immediately after exercise in the present study is the intensity of the exercise to compensate for the lost energy.

As noted above, in the present study at dinner meal and one hour after dinner, plasma levels of AgRP were higher than baseline levels. Compared to that of before dinner and one hour after dinner, the levels of this hormone were higher than before lunch, it might be said, given that it was reported that AgRP has a unique circadian rhythm. On the one hand, this rhythm is consistent with changes in some of the other hormones and eating behavior. On the other hand, it has been reported that AgRP levels increase with the onset of darkness relative to its base levels [28]. Perhaps it can be justified that one of the reasons for increasing plasma levels of AgRP before dinner and one hour after dinner than before lunch and its base level is the beginning of darkness and not the effect of the exercise. Because the plasma levels of this hormone in the control session were also increased before dinner and one hour after dinner than before stages. And given that in both sessions, AgRP plasma levels increased before dinner and one hour after dinner compared to baseline levels and before lunch, and this amount was statistically significant, so it seems that the factor affecting the increase of this hormone is the circadian cycle.

Exercise and appetite (Visual Analog Scale)

In the current study, the rating of hunger and desire to eat decreased immediately after exercise and before lunch in the experimental session, while rating of satiety and fullness were significantly higher immediately after exercise and before lunch; in other words, the desire to eat was reduced. Also, there was no difference in appetite after lunch, before and after dinner, and one hour after dinner in two sessions.

Many studies have reported suppression of hunger after exercise. In agreement with the present study, King et al. showed that, hunger significantly decreased immediately after high intensity exercise [29]. Also, Stephanie et al. found significant decrease in rating of hunger and desire to eat immediately after high intensity exercise in hightrained women, while the rating of satiety and fullness were significantly lower at 60 minutes post-exercise, in other words, rating of desire to eat were significantly higher 60 minutes post-exercise. In their research, the results of the VAS were consistent with the appetite hormone [30]. But, in the present study, the results of the AgRP and VAS were not consistent; in our study, AgRP levels were significantly higher as an orexigenic hormone immediately after exercise. The reason for the lack of consistence between these two factors in the present study can be confirmed by the hypothesis that AgRP is an agent for stimulating the continued eating behavior, not an agent to increase appetite to start eating [31].

Exercise, energy intake and macronutrients

Based on the results obtained in the present study, the energy intake in the exercise session decreased significantly compared to the control session. 
In line with the current research, Sime et al. reviewed the energy intake in overweight individuals following HIIE for the 24 hour and concluded that the energy intake in these individuals was significantly reduced [32]. While Martins et al. did not report any significant difference in the energy intake throughout the day following HIIE and MICE with obese subjects [11]. Also Westerterp et al. found a significant decrease in energy intake 10 minute after two hours of moderate intensity cycling [33]. Most of the previous studies examined energy intake in the laboratory and after food consumptions at single meals and shortly after exercise [34-37]. But in the present study, energy intake was evaluated throughout the day. Also, one session of HIIE, although reducing the consumption of protein, carbohydrates, and fat, this decline was not significant. In this regard, short-term interventions examined the acute effects of an exercise session on macronutrients intake and reported different results, but most of the samples showed a lack of change $[38,39]$. Martins et al. reported no significant change in macronutrients consumption after 60 minutes of moderate-intensity cycling [37].

A limitation of research was that the energy intake was reported by the participants and its correctness depended on the honesty of respondents. But to reduce this limitation, participants were well-trained before starting the study. However, it is suggested that other hormones such as leptin and ghrelin be measured along with AgRP due to the interaction of appetite hormones together.

\section{Conclusion}

In conclusion, this investigation has shown that one session of HIIE, immediately after exercise and lunchtime suppressed appetite. It also declined energy intake throughout the day. AgRP showed an increase immediately after exercise as an appetite stimulating hormone. This increase was not consistent with the VAS. Perhaps a significant increase in the AgRP immediately after exercise may affect factors other than appetite or some of its associated factors. Finally, we concluded that this type of exercise is useful in obese women to control appetite and energy intake throughout the day. But, due to the short-term effects of this type of exercise, it is suggested that the exercise be done two times in the morning and in the evening and close to the main meals.

\section{Acknowledgements}

The authors would like to thank the study participants for their dedication and effort throughout the study.

\section{Conflicts of interest}

The authors declare that they have no competing interest.

\section{References}

1. Matos V, Souza D, Santos V, Medeiros Í, Browne R. Nascimento, P., et al. Acute effects of highintensity interval and moderate-intensity continuous exercise on glp-1, appetite and energy intake in obese men: A crossover trial. Nutrients, 2018; 10.7: 889. https://doi.org/10.3390/nu10070889

2. Lohmann AE, Goodwin PJ, Chlebowski RT, Pan K, Stambolic V, Dowling RJ. Association of obesity-related metabolic disruptions with cancer risk and outcome. Journal of Clinical Oncology, 2016; 34.35: 4249- 4255. https://doi.org/10.1200/JCO.2016.69.6187

3. Atkins JL. Effects of Sarcopenic Obesity on Cardiovascular Disease and All-Cause Mortality. In: Nutrition and Skeletal Muscle. Academic Press, 2019; p. 93-103. https://doi.org/10.1016/B978-0-12-810422-4.00007-5.

4. Ohnishi H, Saitoh S. Obesity and Diabetes Mellitus as Risk Factors for Cardiovascular Disease in the Elderly. In: Health Issues and Care System for the Elderly. Springer, Singapore, 2019; p. 97-106. https://doi.org/10.1007/978-981-13-1762-0 7

5. Avgerinos KI, Spyrou N, Mantzoros CS, Dalamaga M. Obesity and cancer risk: Emerging biological mechanisms and perspectives. Metabolism, 2019; 92: 121-135. https:// doi.org/10.1016/j.metabol.2018.11.001.

6. Piaggi P, Vinales KL, Basolo A, Santini F, Krakoff J. Energy expenditure in the etiology of human obesity: spendthrift and thrifty metabolic phenotypes and energy-sensing mechanisms. Journal of endocrinological investigation, 2018; 41.1: 83-89. https://doi.org/10.1007/s40618-017-0732-9

7. Larsen PS, Donges CE, Guelfi KJ, Smith GC, Adams DR, Duffield R. Effects of aerobic, strength or combined exercise on perceived appetite and appetite-related hormones in inactive middle-aged men. International journal of sport nutrition and exercise metabolism, 2017; 27.5: 389-398. .https://doi.org/10.1123/ijsnem.2017-0144

8. Timper K, Brüning JC. Hypothalamic circuits regulating appetite and energy homeostasis: pathways to obesity. Disease models \& mechanisms, 2017; 10.6: 679-689. https://doi.org/10.1242/dmm.026609

9. Williams G, Cai XJ, Elliott JC, Harrold JA. Anabolic neuropeptides. Physiology \& behavior, 2004, 81.2: 211-222. https://doi.org/10.1016/j.physbeh.2004.02.005

10. Bai F, Sözen MA, Lukiw WJ, Argyropoulos G. Expression of AgRP, NPY, POMC and CART in human fetal and adult hippocampus. Neuropeptides, 2005; 39.4: 439-443. https://doi.org/10.1016/j.npep.2005.02.007.

11. Martins C, Stensvold D, Finlayson G, Holst J, Wisloff U, Kulseng B, et al. Effect of moderate-and high-intensity acute exercise on appetite in obese individuals. Medicine \& Science in Sports \& Exercise, 2015; 47.1: 40-48. https://doi.org/10.1249/MSS.0000000000000372]

12. Hillebrand JJG, De Wied D, Adan RAH. Neuropeptides, food intake and body weight regulation: a hypothalamic focus. Peptides, 2002; 23.12: 2283-2306. https://doi.org/10.1016/S0196-9781(02)00269-3

13. Inui A. Transgenic approach to the study of body weight regulation. Pharmacological reviews, 2000; 52(1): 35-62.]

14. Carnier J, de Mello MT, Ackel-D́Elia C, Corgosinho FC, da Silveira Campos RM, de Lima Sanches P, et al. Aerobic training (AT) is more effective than aerobic plus resistance training (AT+ RT) to improve anorexigenic/orexigenic factors in obese adolescents. Appetite, 2013; 69: 168-173. https://doi.org/10.1016/j.appet.2013.05.018

15. Ghanbari-Niaki A, Abednazari H, Tayebi SM, HossainiKakhakA,KraemerRR. Treadmilltraining enhances ratagoutirelated protein in plasma and reduces ghrelin levels in plasma and soleus muscle. Metabolism, 2009, 58(12): 1747-1752. 
https://doi.org/10.1016/j.metabol.2009.06.002

16. Ghanbari-Niaki A, Nabatchian S, Hedayati M. Plasma agouti-related protein (AGRP), growth hormone, insulin responses to a single circuit-resistance exercise in male college students. Peptides, 2007; 28(5): 1035-1039. https://doi.org/10.1016/j.peptides

17. Bailey DP, Smith LR, Chrismas BC, Taylor L, Stensel $\mathrm{DJ}$, Deighton $\mathrm{K}$, et al. Appetite and gut hormone responses to moderate-intensity continuous exercise versus high-intensity interval exercise, in normoxic and hypoxic conditions. Appetite, 2015; 89: 237-245. https://doi.org/10.1016/j.appet.2015.02.019

18. MiguetM,FillonA, Khammassi M, MasurierJ, Julian V,Pereira $\mathrm{B}$, et al. Appetite, energy intake and food reward responses to an acute High Intensity Interval Exercise in adolescents with obesity. Physiology \& behavior, 2018; 195: 90-97. https://doi.org/10.1016/j.physbeh.2018.07.018

19. Thivel D, Isacco L, Montaurier C, Boirie Y, Duché P, Morio B. The 24-h energy intake of obese adolescents is spontaneously reduced after intensive exercise: a randomized controlled trial in calorimetric chambers. PLoS One, 2012; 7(1): e29840. https://doi.org/10.1371/journal.pone.0029840

20. Flint A, Raben A, Blundell JE, Astrup A. Reproducibility, power and validity of visual analogue scales in assessment of appetite sensations in single test meal studies. International journal of obesity, 2000; 24(1): 38 .

21. Kelly T, Yang W, Chen CS, Reynolds K, He J. Global burden of obesity in 2005 and projections to 2030. Int $J$ Obes. 2008; 32(9): 1431- 1437. https://doi.org/10.1038/ijo.2008.102

22. King JA. Effects of exercise on appetite, food intake and the gastrointestinal hormones Ghrelin and Peptide YY. $[\mathrm{PhD}$ Thesis]. 2010.

23. De Rijke CE, Hillebrand JJG, Verhagen LAW, Roeling TAP, Adan RAH. Hypothalamic neuropeptide expression following chronic food restriction in sedentary and wheel-running rats. Journal of molecular endocrinology, 2005; 35(2): 381-390. https://doi.org/10.1677/jme.1.01808.

24. Katsuki A, Sumida Y, Gabazza EC, Murashima S, Tanaka T, Furuta M, et al. Plasma levels of agouti-related protein are increased in obese men. The Journal of Clinical Endocrinology \& Metabolism, 2001; 86(5): 1921-1924. https://doi.org/10.1210/jcem.86.5.7458

25. Shen CP, Wu KK, Shearman LP, Camacho R, Tota MR, Fong TM, Van der Ploeg LHT. Plasma agouti-related protein level: a possible correlation with fasted and fed states in humans and rats. Journal of neuroendocrinology, 2002; 14(8): 607-610. https://doi.org/10.1046/j.1365-2826.2002.00825.x

26. Ghanbari-Niaki A, Sharifi-Rigi AAH. Serum agouti--related protein (AGRP) response to a single session of circuitresistance exercise at different intensities in male college students. Journal of applied exercise physiology, 2009; 5563 .
27. Qian, S, Chen H, Weingarth, D, Trumbauer ME, Novi DE, Guan, et al. Neither agouti-related protein nor neuropeptide $Y$ is critically required for the regulation of energy homeostasis in mice.Molecularandcellularbiology,2002;22(14):5027-5035. https://doi.org/10.1128/MCB.22.14.5027-5035.2002.

28. Lu XY, Shieh KR, Kabbaj M, Barsh GS, Akil H, Watson SJ. Diurnal rhythm of agouti-related protein and its relation to corticosterone and food intake. Endocrinology, 2002; 143.10: 3905-3915. https://doi.org/10.1210/en.2002-220150. ${ }^{7}$

29. King NA, Burley VJ, Blundell JE. Exercise-induced suppression of appetite: effects on food intake and implications for energy balance. European journal of clinical nutrition, 1994; 48(10): 715-724.

30. Howe S, Hand T, Larson-Meyer D, Austin K, Alexander B, Manore M. No effect of exercise intensity on appetite in highly-trained endurance women. Nutrients, 2016; 8(4): 223. https://doi.org/10.3390/nu8040223

31. Wirth MM, Giraudo SQ. Agouti-related protein in the hypothalamic paraventricular nucleus: effect on feeding. Peptides, 2000; 21(9): 1369-1375. https://doi.org/10.1016/S0196-9781(00)00280-1

32. Sim AY, Wallman KE, Fairchild TJ, Guelfi KJ. Highintensity intermittent exercise attenuates ad-libitum energy intake. International journal of obesity, 2014; 38(3): 417. https://doi.org/10.1038/ijo.2013.102

33. Westerterp-Plantenga MS, Verwegen CR, IJedema MJ, Wijckmans NE, Saris WH. Acute effects of exercise or sauna on appetite in obese and nonobese men. Physiology \& behavior, 1997; 62(6): 1345-1354. https://doi.org/10.1016/S0031-9384(97)00353-3

34. George VA, Morganstein A. Effect of moderate intensity exercise on acute energy intake in normal and overweight females. Appetite, 2003; 40(1): 43-46. https://doi.org/10.1016/S0195-6663(02)00146-0.

35. Erdmann J, Tahbaz R, Lippl F, Wagenpfeil S, Schusdziarra V. Plasma ghrelin levels during exercise - effects of intensity and duration. Regulatory peptides, 2007; 143(1-3): 127-135. https://doi.org/10.1016/j.regpep.2007.05.002

36. Shorten AL, Wallman KE, Guelfi KJ. Acute effect of environmental temperature during exercise on subsequent energy intake in active men. The American journal of clinical nutrition, 2009; 90(5): 1215-1221. https://doi.org/10.3945/ajcn.2009.28162

37. Martins C, Morgan LM, Bloom SR, Robertson MD. Effects of exercise on gut peptides, energy intake and appetite. Journal of Endocrinology, 2007; 193(2): 251-258. https://doi.org/10.1677/JOE-06-0030.

38. Tremblay A, Drapeau V. Physical activity and preference for selected macronutrients. Medicine and science in sports and exercise, 1999; 31(11 Suppl): S584-9. https://doi.org/10.1097/00005768-199911001-00016

39. Elder SJ, Roberts SB. The effects of exercise on food intake and body fatness: a summary of published studies. Nutrition reviews, 2007; 65(1): 1-19. https://doi.org/10.1111/j.1753-4887.2007.tb00263.x 


\section{Information about the authors:}

Khalaj Sepideh; https://orcid.org/0000-0001-8621-4357; Sepideh_khalaj@yahoo.com; Faculty of Physical Education and Sport Sciences, University of Guilan; P.O Box: 1438, Rasht, Iran.

Mirzaei Bahman; (corresponding author); https://orcid.org/0000-0003-3723-7434; mirzaei@united-world-wrestling.org; Faculty of Physical Education and Sport Sciences, University of Guilan; P.O Box: 1438, Rasht, Iran.

Cite this article as:

Sepideh Khalaj, Bahman Mirzaei. Does an acute bout of high intensity interval exercise suppress appetite in obese women? Pedagogy of physical culture and sports, 2020;24(4):181-188.

https://doi.org/10.15561/26649837.2020.0405

This is an Open Access article distributed under the terms of the Creative Commons Attribution License, which permits unrestricted use, distribution, and reproduction in any medium, provided the original work is properly cited (http://creativecommons.org/licenses/by/4.0/deed.en).

Received: 20.12.2019

Accepted: 26.01.2020; Published: 30.08 .2020 